NASA Technical Memorandum 105698

AIAA-92-3790

\title{
Internal Reversing Flow in a Tailpipe Offtake Configuration for SSTOVL Aircraft
}

Jack G. McArdle and Barbara S. Esker

Lewis Research Center

Cleveland, Ohio

and

James A. Rhodes

McDonnell Aircraft Company

St. Louis, Missouri

Prepared for the

28th Joint Propulsion Conference and Exhibit cosponsored by the AIAA, SAE, ASME, and ASEE

Nashville, Tennessee, July 6-8, 1992 


\title{
INTERNAL REVERSING FLOW IN A TAILPIPE OFFTAKE
}

\section{CONFIGURATION FOR SSTOVL AIRCRAFT}

\author{
Jack G. McArdle and Barbara S. Esker \\ National Aeronautics and Space Administration \\ Lewis Research Center \\ Cleveland, Ohio 44135 \\ James A. Rhodes \\ McDonnell Aircraft Company \\ St. Louis, Missouri 63166-0516
}

\section{Abstract}

A generic one-third scale model of a tailpipe offtake system for a supersonic short takeoff vertical landing (SSTOVL) aircraft was tested at the NASA Lewis Research Center Powered Lift Facility. The model consisted of a tailpipe with twin elbows, offtake ducts, and flow control nozzles, plus a small ventral nozzle and a blind flange to simulate a blocked cruise nozzle. The offtake flow turned through a total angle of $177^{\circ}$ relative to the tailpipe inlet axis. The flow split was 45 percent to each offtake and 10 percent to the ventral nozzle. The main test objective was to collect data for comparison to the performance of the same configuration predicted by a computational fluid dynamics (CFD) analysis. This paper gives the experimental results only-the analytical results are published in a separate paper.

Performance tests were made with unheated air at tailpipe-to-ambient pressure ratios up to 5 . The total pressure loss through the offtakes was as high as $\mathbf{1 5 . 5}$ percent. All test results are shown as graphs, contour plots, and wall pressure distributions. The complex flow patterns in the tailpipe and elbows at the offtake openings are described with traversing flow angle probe and paint streak flow visualization data.

\section{Introduction}

Supersonic short takeoff vertical landing (SSTOVL) aircraft are within technical reach of meeting future military requirements. The NASA Lewis Research Center is involved in several programs that advance the technology needed for these aircraft-such as integrated controls, propulsion exhaust systems, and hot gas reingestion during vertical flight near the ground.

Several proposed SSTOVL powered lift concepts are based on blocking the cruise exhaust nozzle and redirecting engine gas forward to lift thrusters during landing or hover flight. In addition, a small ventral nozzle might be needed to balance vertical forces or to provide pitch trim and control. A typical concept is sketched in Fig. 1(a). The lift thrusters could be ejectors, burners, lift nozzles, or gas-driven lift fans. In every case, the available lift is directly reduced by the pressure loss in the tailpipe offtakes and ducts leading to the thrusters. The flow patterns causing pressure loss are known to be very complex.

One of the NASA Lewis SSTOVL technology goals is to determine if the flow behavior in various exhaust configurations can be modeled and predicted successfully with computational fluid dynamics (CFD) programs. To this end, the internal flow patterns and performance of a generic tailpipe, closed at the aft end and having a large ventral nozzle, were computed at Lewis with a program called PARC3D. ${ }^{1}$ The results ${ }^{2,3}$ compared very favorably with experimental data from the same configuration. For instance, the predicted ventral nozzle discharge and thrust coefficients were only about 1 percentage point greater than the measured values. In addition, the internal flow patterns shown by experimental paint streaks and CFD flow visualization images were remarkably similar. This same computationalplus-experimental approach has now been extended to a generic tailpipe offtake configuration in a joint program with the McDonnell Aircraft Company. In the joint program, Lewis built and tested a one-third-scale model, and McDonnell Aircraft performed a CFD analysis of the same configuration. The model, sketched in Fig. 1(b), was designed for ease in generating a grid for the CFD analysis. It retained all the essential features of an SSTOVL aircraft with this type of powered lift system, except for thrusters. The model consisted of a tailpipe with twin elbows, offtake ducts, and flow-control nozzles, plus a small ventral nozzle and a blind flange to simulate a blocked cruise nozzle. Cutouts in the tailpipe wall for the offtake and ventral ducts did not contain simulated shutoff valves. All ducts were round in cross section. Offtake flows were turned through $177^{\circ}$ relative to the tailpipe inlet axis. The total tailpipe flow 
was split nominally 45 percent to each offtake and 10 percent to the ventral nozzle. The tailpipe Mach number was 0.3. For the CFD analysis, McDonnell Aircraft modeled and analyzed the same configuration by using the McDonnell Aircraft Computational Grid System (MACGS) and Navier Stokes Time Dependent (NASTD) codes.

This paper presents the results of the experimental work. (The CFD programs and computational results are described in detail in Ref. 4). At the NASA Lewis Powered Lift Facility, the model was tested with unheated air over a range of tailpipe-to-ambient pressure ratios up to 5. Performance criteria, such as system pressure loss and duct Mach number, are reported over the range of measured pressure ratios for two preliminary (smaller) nozzle sizes as well as for the final nozzle. Details of performance, such as wall pressures, flow patterns, duct total-pressure contours, and elbow inflow direction and velocity are shown for the final nozzle size at a tailpipe pressure ratio of 4.5. Some changes in performance and internal flow patterns were noted when the ventral nozzle was closed off. Thrust produced by the model was not measured, but thrust is not important to understanding flow behavior through the offtake system.

\section{Apparatus}

\section{Experimental Model}

A schematic of the experimental model is shown in Fig. 2. The first section of this model was a reducer section between the facility 24 in. diameter piping and the model tailpipe. This reducer section contained flow straighteners, a screen, and a boundary layer trip to ensure uniform flow with a turbulent boundary layer into the model tailpipe. The model tailpipe had a 13.5 in. diameter, which is approximately one-third the diameter of modern military engines. The aft end of the tailpipe was blocked with a blind flange to simulate a closed cruise nozzle.

Attached to the tailpipe were two identical circular-cross-section offtakes located $180^{\circ}$ apart. The offtake duct and tailpipe centerlines were all located in the same horizontal plane. The offtakes intersected the tailpipe perpendicularly and had unrounded edges at the intersections. Each offtake consisted of a 10-in.diameter elbow and straight duct and a nozzle. The elbow had a 10 -in. centerline radius of curvature and an $87^{\circ}$ arc. The straight ducts, attached to the elbows, thereby were canted $3^{\circ}$ away from the tailpipe to avoid interference with facility flanges. At the end of the straight ducts were American Society of Mechanical Engineers (ASME) flow-measuring nozzles ${ }^{5}$ to provide back pressure for the system and to meter the offtake flow.

A small ventral duct was located in the vertical plane aft of the offtakes. The duct was 4.5 in. in diameter and had unrounded edges at the tailpipe intersection. The ventral nozzle had a $15^{\circ}$ half-angle conical shape. Photographs of the model are shown in Fig. 3.

\section{Facility}

The experimental model was tested on the NASA Lewis Powered Lift Facility (PLF). The PLF is a large thrust stand capable of measuring forces in the thrust, vertical, and lateral directions, as well as moments about the three axes; however, the force-measuring capability of the facility was not used for these tests. The model was supplied with high-pressure air, at approximately $70^{\circ} \mathrm{F}$, from the Lewis central air system. The total facility airflow was measured upstream of the PLF with an ASME nozzle located in the air supply piping. The accuracy with which this airflow was measured was \pm 0.5 percent.

\section{Instrumentation and Data}

\section{Model Instrumentation}

Philosophy.-Instrumentation was located throughout the model to provide data for quantitative comparison with CFD results. Accordingly, wall pressure taps were installed at many locations along the flowpath. Free-stream total pressure rakes with tubes located on centers of equal area were located at several stations. Additional total pressure tubes were located in the boundary later. Rakes were always the same in each of the offtake ducts in order to keep equal flow in both sides. Except for a flow angle probe for traverses, no rakes were placed at an offtake entrance lest a rake impede or alter the offtake inflow. Ambient pressure, inlet air total temperature, and an independent total airflow measurement were obtained from existing facility equipment.

Pressure and temperature instrumentation.-The model station and instrumentation diagrams are given in Fig. 4. Flow total temperature was assumed to be constant through the model, so stream thermocouples were not used. Pressure transducers, having calculated installed frequency response flat ( \pm 5 percent) to $180 \mathrm{~Hz}$, were used to measure dynamic pressures. The model contained up to 248 steady-state pressure and 2 wall temperature measurements.

Flow angle probe.-A photograph of a probe used to measure stream flow angles relative to the sensing tip, 
plus stream total pressure and Mach number, is shown in Fig. 5. The probe was mounted in a calibrated actuator to traverse the offtake at the elbow entrance. The sensing tip was the same as a conventional 5 -port flow angle probe ${ }^{6}$ but was mounted $45^{\circ}$ to the stem in anticipation of small flow approach angles (see angle definition in Appendix A) at the offtake opening. A similar probe, but with the sensing tip perpendicular to the stem, was used to traverse the offtake duct at the elbow exit. Each probe was calibrated in an open jet at Mach numbers of $0.3,0.5$, and 0.8 , at positions equivalent to swirl angles of $-10^{\circ}, 0^{\circ}$, and $+10^{\circ}$, and at approach angles from $-30^{\circ}$ to $+30^{\circ}$. During testing the stem was rotated by the actuator to keep the sensed swirl angle small. The calibration data were used to compute stream conditions from the experimental measurements through the use of an iterative computational procedure.

\section{Data Recording and Processing}

Steady-state data. - After airflow in the model had become steady, 20 scans of the instrument list were made at the rate of 1 scan per second. These data were converted to engineering units, averaged, and recorded by the laboratory central data system. The final computations were batch processed from the averaged data on a mainframe computer.

Total airflow was measured with the facility ASME flow-measuring nozzle, using ASME recommended procedures and coefficients.

Ventral nozzle flow was computed with isentropic flow equations and necessary measured data, using discharge coefficients per Ref. 7 (0.970 for a hard-choked $15^{\circ}$ conical nozzle).

Offtake flow in each side was computed using ASME coefficients ${ }^{5}$ and necessary measured data. The final nozzle sizes had a 0.71 throat-to-inlet diameter ratio, which is near the maximum recommended by ASME. The throat Reynolds number was as high as $8.4 \times 10^{6}$

Dynamic pressure data.-Outputs from the dynamic pressure transducers were recorded on magnetic tape along with a time code and calibration signals. The transducer data were processed into $1.25-\mathrm{Hz}$ narrowband spectra with a spectrum analyzer.

\section{$\underline{\text { Procedure }}$}

$\underline{\text { Preliminary model sizing tests }}$

Because the total pressure loss through the tailpipe and offtake system was not known before the perfor- mance tests, the nozzle areas needed to achieve the desired flow conditions could not be calculated in advance. The desired flow conditions in the model at $\mathrm{PR}_{5}=4.5$ were as follows (see Appendix A for symbols and definitions):

Tailpipe Mach number, $\mathrm{M}_{5}=0.3$

Offtake duct Mach number, $\mathrm{M}_{\mathrm{d}}=0.3$

Offtake flow, $\mathrm{w}_{\mathrm{d}}=45$-percent total flow, $\mathrm{w}_{5}$ Ventral flow, $w_{\mathbf{v}}=10$-percent total flow, $w_{5}$

The model size was based on a 13.5-in. tailpipe diameter so that existing hardware from a previous test program could be used. The offtake duct diameter was the diameter of commercial pipe that was closest to the duct diameter estimated to give all the desired flow conditions. (This initial estimate came from calculations that assumed choked nozzle flows and $1.0 \mathrm{q}_{5}$ pressure loss in the offtake ducts, where $q_{5}$ is the tailpipe dynamic pressure. This estimate came from experience with ventral nozzles reported in Ref. 2 , but it turned out to be inappropriate as shown later in this paper).

The nozzles were sized in trial-and-error preliminary experiments. At first the three nozzles were purposely undersized. A performance test was run to measure duct Mach numbers and flow rates. The resulting data were extrapolated to choose larger nozzle areas. The larger nozzles were machined to the required geometric shapes. This process was repeated to set the final nozzle sizes. The final nozzle sizes were 39.6 in. $^{2}$ for each offtake nozzle and 8.09 in. $^{2}$ for the ventral nozzle. The final areas were 22.6 and 5.6 percent, respectively, of the tailpipe flow area.

\section{Performance Tests}

Performance testing consisted of measuring the internal flow conditions over a range of tailpipe total-toambient pressure ratios, $\mathrm{PR}_{5}$, from 1.0 to 5.0. For each $\mathrm{PR}_{5}$, mass flow rates (actual and ideal), duct Mach numbers, and area-averaged total pressure at the various model stations were computed.

\section{Flow Pattern Tests}

Flow pattern tests were done after the final nozzle exit areas had been determined. Flow angle surveys were made by moving the flow angle probe in 0.5 -in. increments across the horizontal diameter at elbow Stations $5 \mathrm{~A}$ and 5B. Flow angles in two planes were determined on the basis of the pressure distribution among the five tubes in the probe.

Flow visualization paint streaks were made by placing small dabs of thick oily paint in a regular pattern on the inside surface of the model. Airflow was 
started quickly, held for approximately $1 \mathrm{~min}$, and shut off. The paint ran along flow streamlines, and the resulting streaks were photographed for record.

\section{$\underline{\text { Results and Discussion }}$}

\section{Performance}

This section presents and discusses flow, Mach number, and pressure loss results for the model with two preliminary and the final nozzle sizes at $\mathrm{PR}_{5}$ 's up to 5 . In addition, the total pressure distributions at the tailpipe, ventral nozzle, and offtake stations are shown for $\mathrm{PR}_{5}=4.5$. A list of symbols and definitions is given in Appendix A.

Airflow.-Flow rates referred to Station 5 are shown in Fig. 6(a) for the final nozzle sizes. The tailpipe (total) flow rate, $\mathrm{w}_{5}$, was measured by the facility equipment, and the offtake, $w_{n}$, and ventral nozzle, $w_{v}$, flow rates were measured by the nozzles on the model. The offtake flow rates were the same when the ventral nozzle was open or closed off by a blind flange at its inlet. Although not shown in the figure, the flow typically was the same in each offtake side within 0.12 percent of $w_{5}$. All the flow rates were constant after the offtake nozzles choked.

The measured tailpipe flow was slightly less than the sum of the measured outflows. This difference, shown in Fig. 6(b), was as much as 2.2 percent of $\mathrm{w}_{5}$. In this regard, Ref. 6 points out that the inaccuracy of the discharge coefficient for sonic flow in the (ASME) offtake nozzles is \pm 2 percent. Previously, the facility equipment had measured flow within \pm 0.5 -percent inaccuracy with a choked calibration nozzle, having similar flow capacity, mounted on the PLF stand. Thus, the facility is believed to provide the more accurate flow measurement. However, the reported offtake flow values in Fig. 6(a) could be as much as 2.7-percent too high. Ventral nozzle flow inaccuracy is not known, but because of the distorted total pressure measured at the nozzle inlet (discussed in a later section), the inaccuracy is estimated to be within \pm 2 percent.

Offtake ducts.- The performance of the offtake ducts measured in the two preliminary and the final nozzle sizing tests described in a preceding section is shown in Fig. 7. For each nozzle area, the pressure loss and the Mach number at the end of the offtake duct, Station 5 C, increased with the tailpipe pressure ratio and became nearly constant after the nozzles choked. This behavior is not unusual, although the magnitude of the pressure loss, up to 15.5 percent of the tailpipe pressure, is considerably greater than the 1.5 -percent loss reported in tests of elbows with uniform inflow. ${ }^{8}$ Although not shown in Fig. 7, the pressure loss was the same in each offtake within 0.2 percent of the tailpipe pressure. The flow split, as a percentage of tailpipe flow, was satisfactorily close to the desired value.

The performance of the model with the ventral nozzle closed is also shown in Fig. 7. In comparison to the same configuration with the ventral nozzle open, the tailpipe Mach number decreased because of reduced total flow, but the offtake flow rate, Mach number, and pressure loss were about the same. This result implies that, for a given geometric configuration with small throughflow or ventral flow, the offtake turning loss depends mainly on the offtake flow, rather than on some tailpipe parameter such as Mach number. However, more data are needed to trust such a generalization.

The offtake pressure loss expressed in terms of tailpipe dynamic pressure is shown in Fig. 8. The results of the tests with the ventral nozzle open fall in a relatively narrow band centered at $2.53 \mathrm{q}_{5}$. The band includes all the data for both unchoked and choked nozzle flows. However, with the ventral nozzle closed the pressure loss increased to approximately $3.25 \mathrm{q}_{5}$, but $\mathrm{q}_{5}$ was less because the total flow rate was reduced.

Ventral duct.- The ventral duct performance is shown in Fig. 9. These results were obtained in the nozzle sizing tests discussed previously. The performance trends were the same as measured for the offtake ducts. The maximum pressure loss was 8.4 percent of the tailpipe pressure, and all the pressure loss data fell in a relatively narrow band centered at $1.35 q_{5}$. The flow split was satisfactory.

Total pressure distribution.-The total pressures measured at various stations in the model are shown in Fig. 10 for $\mathrm{PR}_{5}=4.5$. The contour plots at Stations $5 \mathrm{~B}$ and $5 \mathrm{C}$ were made by combining the data from two test readings, one with the rakes positioned as shown in Fig. 4 , the other with the same rakes rotated $45^{\circ}$ in the measuring plane. Because of geometric and flow similarities, these results are applicable to either offtake.

The tailpipe inflow at Station 5 (Fig. 10(a)) had a thin boundary layer and uniform total pressure in the core. The boundary layer was presumed to be turbulent because of the boundary layer trip located approximately one tailpipe diameter ahead of Station 5 (Fig. 2 and Ref. 9).

At the elbow exit (Station 5B), the highest total pressure was measured near the outside wall. As will be shown in a subsequent figure, the static pressure at this station was nearly uniform; therefore, a large velocity gradient existed with the greatest velocity and flow concentrated near the outside wall of the elbow. The 
flow then diffused as it traveled down the duct, and the total pressure became much more uniform at Station 5C, the end of the duct and entrance to the offtake nozzle.

The distribution of the offtake total pressure loss is given in Fig. 10(b). Nearly all the loss occurred as the flow turned from the tailpipe Station 5 into and through the elbow to Station 5B. The loss in the straight duct from Station $5 \mathrm{~B}$ to Station $5 \mathrm{C}$ was very small.

The total pressure contours at the ventral nozzle inlet are shown in Fig. 11. The contours were estimated from the rake pressure data. Pressure and flow were strongest in the aft part of the ventral duct. Reverse flow probably occurred near the front wall because the measured wall static pressure was greater than the nearby rake total pressures.

\section{Wall Pressures}

The wall pressures measured at taps located throughout the model are reported in this section as ratios of the tailpipe total pressure, $\mathrm{P}_{5}$, at $\mathrm{PR}_{5}=\mathbf{4 . 5}$. Data are given for both the ventral-nozzle-open and ventral-nozzle-closed cases. These wall pressures can aid in understanding flow behavior in the tailpipe and offtakes.

Tailpipe.-The tailpipe wall pressure distribution is shown in Fig. 12. The pressure differences from sideto-side, shown in the top view (Fig. 12(a)), were small for both the ventral-nozzle-open and ventral-nozzleclosed cases, consistent with flow equality in the offtakes. In general, pressures were somewhat higher with the ventral nozzle closed, mostly because the total flow rate and Mach number decreased. Pressures were lowest near the offtake openings because the flow accelerated to turn into the openings. Further aft in the tailpipe, the wall pressures, including the pressure on the blind flange, were less than the Station 5 total pressure. This decrement is probably the diffusion loss of the air that flowed into the blocked tailpipe aft of the offtake openings. Pressures at the closed end of the tailpipe were also measured by rakes (similar to those used at Station 5) that were mounted at the blind flange for a special test to determine if a pressure gradient existed there. No pressure gradient was found, and pressures measured on the rake were the same as those measured on the center of the blind flange. Calculations using this total pressure show that the Mach number of the recirculating air at the walls in the blocked part of the tailpipe was on the order of 0.05 .

The pressure differences top-to-bottom in the tailpipe (Fig. 12(b)) were similar to those side-to-side except near the ventral opening and at Station 5 . At Station 5 the pressure on the bottom of the tailpipe was always measurably greater than on the top. No reason related to the PLF facility configuration or installation was found. (For verification, later tests with a simple axial exhaust nozzle mounted in place of the offtake model showed no difference between these same top-tobottom measurements. Therefore, the higher pressure on the bottom of the tailpipe seems related to flow turning into the offtake openings).

Pressures measured on the tailpipe wall around the offtake opening and in the offtake duct just downstream of the opening (Station 5A) are given in Fig. 12(c). The highest pressures always occurred in the upper right quadrant. The lowest pressures occurred at the front edge of the opening, showing that velocity probably was highest there. The figure shows that pressures on the tailpipe wall were generally higher than wall pressures corresponding radially at Station 5A. These pressure differences tended to drive flow into the offtake, but as will be discussed in a later section, this is not the most important inflow pattern.

Although the pressures measured with the ventral nozzle closed generally were similar to those with the nozzle open, small differences can be noted. These differences are consonant with altered flow patterns, which are shown in the section Flow Patterns.

Offtakes.-Wall pressures measured in an offtake elbow and duct are shown in Fig. 13. Just downstream of the offtake opening, the pressures were always greater on the outer wall than on the inner wall, indicating that the flow was always turning as it moved through the elbow and the first part of the long straight duct. At the end of the duct the pressure was the same all around the wall, consistent with the previous observation that the flow diffused through the duct and became more nearly uniform at the offtake nozzle entrance. There is no evidence that the flow was choked anywhere in the system ahead of the nozzles. The highest pressure, $0.87 \mathrm{P}_{5}$, occurred over a relatively small wall area, so cooling the offtake elbows and ducts with bypass air in a turbofan installation would be feasible.

Dynamic pressures.-Dynamic pressures at the offtake openings and at the center of the blind flange were measured with high-frequency-response transducers (Fig. 4). Periodic fluctuations at these locations would expose interesting oscillating flows or resonances in the system not detected by the steady-state instrumentation.

Spectra from the transducers at the offtake openings (Fig. 14(a) and (b)) show some periodic activity between 15 and $35 \mathrm{~Hz}$. However, the spikes result in 
only about a 0.01 Mach number change in flow velocity, which does not seem to represent a significant flow oscillation.

If a standing wave were present in the closed end of the tailpipe, maximum pressure variations would occur at the blind flange. The quarter-wave-length frequency is between 64 and $80 \mathrm{~Hz}$ for waves originating at the offtake opening. The spectra from the transducer at the blind flange (Fig. 14(c)) do not show spikes near these frequencies, so this type of resonance was not present.

\section{Flow Patterns}

In-stream flow patterns were measured with the calibrated flow angle probe traversed across an offtake duct at Stations $5 \mathrm{~A}$ and $5 \mathrm{~B}$ at a tailpipe pressure of ratio 4.5. Wall flow patterns in and around the offtake entrance were obtained from flow visualization paint streaks. The flow patterns complement the pressure data and contour plots given in previous figures.

Elbow entrance traverse.- - Results of the flow angle probe traverse at the elbow entrance (Station 5A) are shown in Fig. 15 for the ventral nozzle both open and closed. The traverses were made on the horizontal centerline to within 1 in. of each wall and started at the aft edge of the opening.

The total pressure ratio (Fig. 15(a)) is the ratio of the computed probe total pressure to the Station 5 total pressure. For the ventral-nozzle-open case the pressure was generally high in the aft and central parts of the opening; in fact, the pressure showed little or no loss from Station 5 over part of the traverse path. When the ventral nozzle was closed, the pressure dipped to a much lower level about 3.5 in. from the aft edge, but otherwise was similar to the traverse with the ventral nozzle open. This change in total pressure distribution hints that much of the offtake inflow pattern changed with the ventral nozzle closed, but the pressure loss from Station 5 to Station $5 \mathrm{C}$ was the same whether the ventral nozzle was open or closed (Fig. 7). No explanation is known for this unexpected result.

The Mach number variation across the opening computed from the traverse data is shown in Fig. 15(b). In the aft part of the opening the Mach number was about 0.4 and gradually increased with traverse distance to a peak value of 0.73 . Calculations using these results plus the total pressure data in Fig. 15(a) reveal that the stream static pressure decreased along the traverse path. The Mach number fell off rapidly in the turning flow near the front edge of the opening.
The angles at which the flow entered the offtake opening are called herein the approach angle (measured in the horizontal plane) and the swirl angle (measured in the vertical plane). These measured angles are shown in Fig. 15(c) and (d), respectively. Flow generally approached the opening at angles between $40^{\circ}$ and $65^{\circ}$, and up to $70^{\circ}$ (more nearly normal to the tailpipe wall) at the aft and front edges. These measurements show that the flow had begun to turn in the tailpipe, the same as with the ventral nozzle model reported in Ref. 2 . Flow swirled downward in the aft part of the opening, then in the opposite direction at the central part. The swirl disappeared near the front edge. The traverse results were similar for both the ventral-nozzle-open and ventral-nozzle-closed cases.

Elbow exit traverse.-Results of the flow angle probe traverse at the elbow exit (Station 5B) are shown in Fig. 16 for the ventral nozzle open. The traverse was made on the horizontal centerline and started at the outside wall of the offtake duct.

The total pressure ratio and Mach number (Fig. 16(a) and (b)) are both highest at the outside wall, decrease to lower values near the central part of the duct, then rise again near the inner wall. Calculations using these data show that the stream static pressure was higher near the outside wall, which is the same trend shown in Fig. 13. The total pressure gradient is very similar to the contour plot data (Fig. 10) obtained from fixed rakes.

In the duct, the flow path is defined herein by angles relative to the duct axis. The flow angle is measured in the horizontal plane, and the swirl angle is measured in the vertical plane. At Station $5 \mathrm{~B}$ the flow angle was small across the entire duct. The swirl angle was about $+15^{\circ}$ at the outside part of the duct; it then decreased to $-30^{\circ}$ near the inside wall. This result is interpreted as identifying a counterclockwise flow rotation (looking into the flow). In comparison to Station $5 \mathrm{~A}$ (Fig. 15), the flow is much more uniform.

Flow visualization.-The photographs in Fig. 17 show flow visualization streaks drawn on a scale mockup of the model cut in half on the (vertical) plane of symmetry. Several photographs of the experimental paint streaks from a test with the ventral nozzle open were used as a guide to draw the streaks on the mockup.

Figure $17(\mathrm{a})$ shows streaks on the tailpipe wall. The inflow streaks at Station 5 were axial in direction, and the flow was uniform (see Fig. 10(a)). The flow into the offtake opening, envisioned with the aid of pressure and traverse data already presented, was as 
follows. Much of the flow impacted the aft offtake wall just inside the opening (near Station 5A), then followed the elbow wall downstream. Some of this flow, in the upper right quadrant, spilled back into the tailpipe and swirled in a clockwise manner to reenter the opening in the lower right and bottom quadrants. Other streaks show that flow entered radially around most of the opening, as expected from the wall pressure differentials given in Fig. 12(c). The flow entering the ventral duct probably separated at the front of the opening, as in the ventral nozzle model tests reported in Ref. 2, and impacted the aft wall of that opening (see Fig. 11). The streaks indicate that all the ventral flow entered the duct from the front side, but they do not indicate whether the flow came from the central or wall regions of the tailpipe. Further aft in the tailpipe, streaks show that the flow continued to move toward the blind flange, but some of the streaks suggest that it broke into complex three-dimensional swirling flows. In any case, by continuity there must have been flow in the reverse direction elsewhere in the tailpipe.

In Fig. 17(b) and (c), parts of the elbow have been removed to show streaks inside the elbow. As stated previously, much of the flow that impacted the aft wall of the opening flowed downstream along the elbow wall. Streaks illustrating this flow can be seen in Fig. 17(b). In addition, some of the flow ran along the lower wall of the elbow, as shown in Fig. 17 (c), and joined with the swirling flow entering from the tailpipe. This combined flow moved across the wall toward the elbow exit, without following the wall curvature, and still had a negative swirl angle at the exit (see Fig. 16(d)). However, this pattern probably contributed to the more uniform total pressure measured at the elbow exit (Fig. 16(a)).

\section{Conclusions}

A generic one-third scale model of a tailpipe offtake system for an SSTOVL aircraft was tested at the NASA Lewis Powered Lift Facility. The flow split was 45 percent to each of two offtakes and 10 percent to a small ventral nozzle. Offtake flow turned through a total of $177^{\circ}$. The tests were performed over a range of tailpipe-to-ambient pressure ratios up to 5 . Important test results are as follows:

1. Pressure loss in the offtake ducting was $\mathbf{1 5 . 5}$ percent of the tailpipe total pressure at a tailpipe Mach number of 0.307 when the offtake flow-control nozzles were choked. This is equivalent to a loss of 2.5 times the tailpipe dynamic pressure.

2. When the ventral nozzle was closed off, the offtake flow and pressure loss remained the same, but the offtake inflow pattern changed. The data obtained in these tests did not reveal the details of this behavior.

3. Nearly all the pressure loss occurred in turning the flow from the tailpipe into and through the elbows.

4. No significant periodic pressure fluctuations were measured at the offtake openings or at the blocked end of the tailpipe.

5. Wall pressures throughout the tailpipe were less than 96 percent of tailpipe total pressure, and in the offtake ducting were less than 88 percent.

6. Flow patterns at the offtake opening were complex. Much of the flow entered the aft part of the opening and followed the outside wall of the elbow downstream. Other flow swirled in to the bottom part of the opening and filled in the lower-pressure region near the inside wall. The flow was reasonably uniform at the ends of the long offtake ducts.

7. Ventral flow was concentrated in the aft part of the duct and was not uniform at the ventral nozzle inlet because the duct was short.

The generalized results of these tests that have application to flight hardware design are as follows:

1. Turning aids at the offtake openings, such as rounded edges or guide vanes, are needed to reduce offtake pressure loss.

2. Turning vanes may have to be tailored to variations in flow approach angles at the tailpipe openings. formity.

3. Ducts should be long to promote flow uni-

4. Wall pressures are low enough that turbofan engine bypass air probably can be used for wall cooling.

5. A small amount of ventral flow may not affect the pressure loss in an offtake system.

\section{Appendix A-Symbols and Definitions}

(Figure 2 illustrates geometric symbols.)

A area, in. ${ }^{2}$

D diameter, in.

M Mach number

$\left(\right.$ for air, $\left.M=\sqrt{5\left[\left(P / p_{w}\right)^{0.2857}-1\right]}\right)$ 
P total pressure, psia

p static pressure, psia

PR pressure ratio relative to ambient pressure

q dynamic pressure, psia

$\mathrm{R}$ radius of curvature at elbow centerline, in.

w measured airflow rate, pps

Subscripts:

d offtake duct

n offtake nozzle

tp tailpipe

$\mathrm{v}$ ventral nozzle

w wall static pressure

$\delta$ ratio of pressure to standard-day pressure, $14.696 \mathrm{lb} /$ in. $^{2}$

$\theta \quad$ ratio of temperature to standard-day temperature, $518.7^{\circ} \mathrm{R}$

5

5A station numbers-see Fig. 4 (if followed

$5 \mathrm{~B}$ by 1 or 2 , refers to a particular offtake

$5 \mathrm{C}$ side)

$5 \mathrm{CS}$

Definitions:

Swirl angle

Angle between the flow vector and the offtake centerline measured in a plane normal to the traverse path

Approach angle

Angle between the flow vector and the tailpipe centerline measured in a horizontal plane

Flow angle

Angle between the flow vector and the offtake duct centerline measured in a horizontal plane

\section{$\underline{\text { References }}$}

1. Cooper, G.K., and Sirbaugh, J., "The PARC Distinction: A Practical Flow Solver," AIAA Paper 902002, July 1990.

2. McArdle, J.G., and Smith, C.F., "Experimental and Analytical Study of Close-Coupled Ventral Nozzles for ASTOVL Aircraft," NASA TM-103170, 1990.

3. Smith, C.F., and McArdle, J.G., "Analysis of Internal Flow in a Ventral Nozzle for STOVL Aircraft," AIAA Paper 90-1899, July 1990.

4. Rhodes, J.A., Esker, B.S., and Smith, C.F., "Computational and Experimental Investigation of Subsonic Internal Reversing Flows." To be published as AIAA Paper 92-3791, July 1992.

5. Bean, H.S., "Fluid Meters-Their Theory and Application," Sixth Edition, ASME, New York, 1971.

6. Krause, L.N., and Dudzinski, T.J., "Flow-Direction Measurement With Fixed-Position Probes in Subsonic Flow Over a Range of Reynolds Numbers," NASA TM-X-1904, 1969.

7. Stitt, L.E., "Exhaust Nozzles for Propulsion Systems With Emphasis on Supersonic Cruise Aircraft," NASA RP-1235, 1990.

8. Higginbotham, J.T., Wood, C.C., and Valentine, E.F., "A Study of the High-Speed Performance Characteristics of $90^{\circ}$ Bends in Circular Ducts," NACA TN-3696, 1956.

9. Raman, G., Zaman, K.B.M.Q., and Rice, E.J., "Initial Turbulence Effect on Jet Evolution With and Without Tonal Excitation," AIAA Paper 872725 , Oct. 1987. 


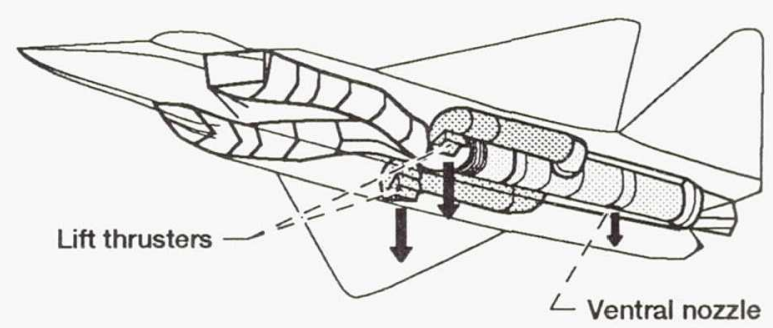

(a) SSTOVL aircraft.

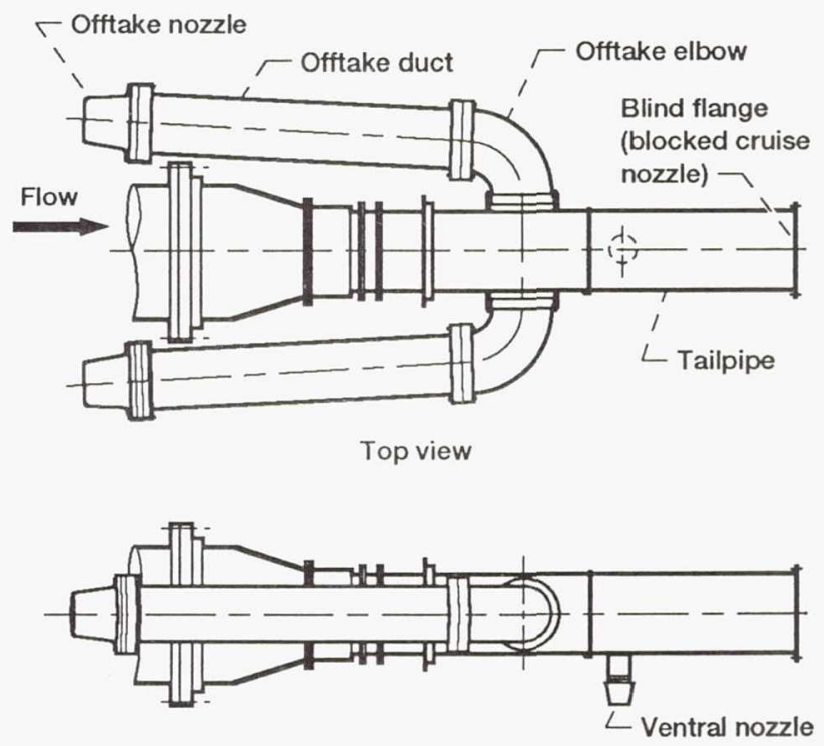

Side view

(b) Model tested.

Fig. 1. - SSTOVL powered lift system using engine exhaust gas.

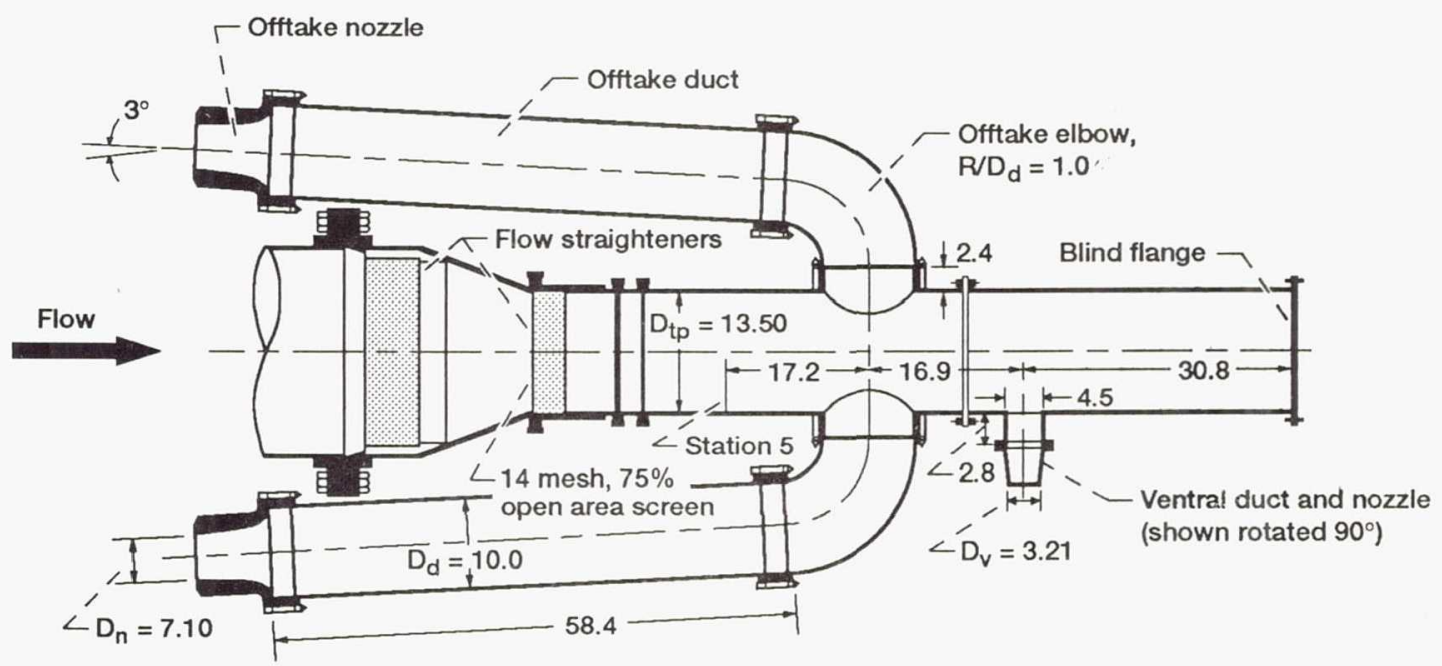

Fig. 2.-Top view of tailpipe offtake duct model. All dimensions given in inches. 


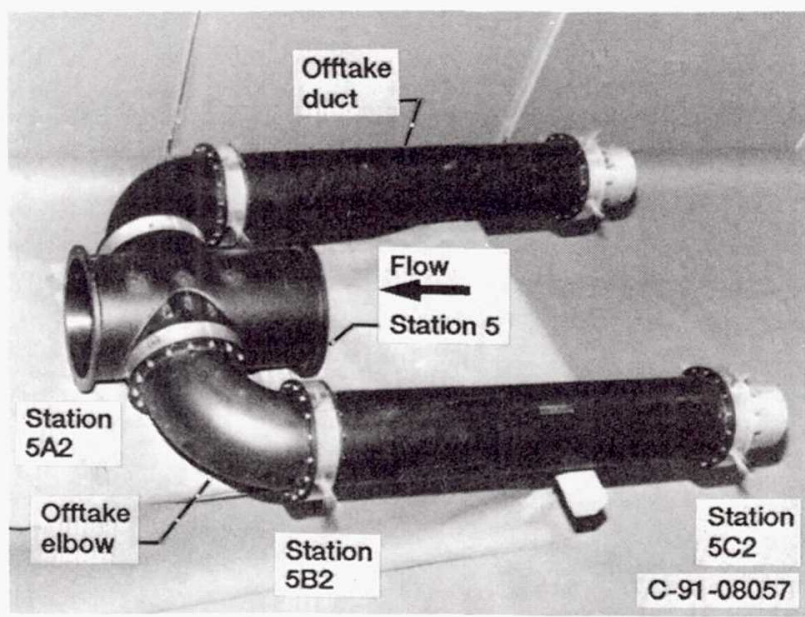

(a) Model without blocked tailpipe.

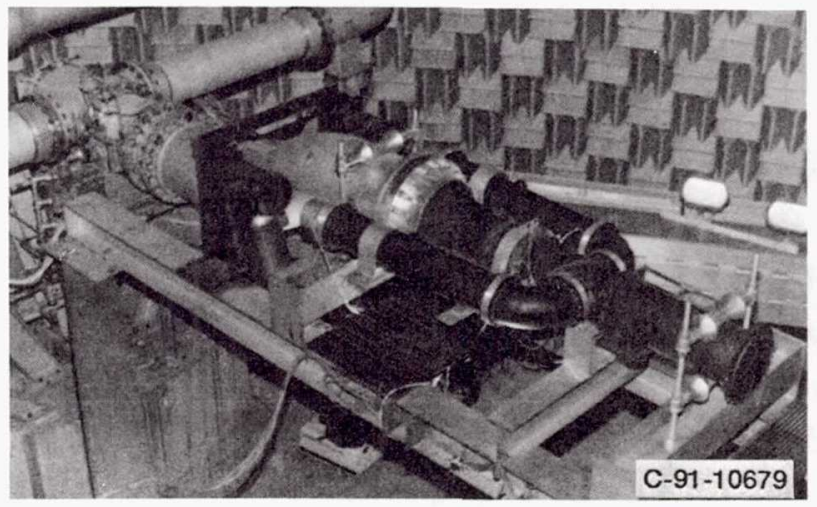

(b) Model mounted on the NASA Lewis Powered Lift Facility.

Fig. 3.-Tailpipe offtake duct model. 


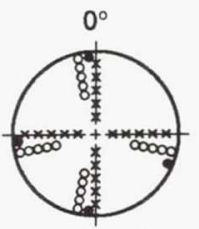

Station 5 Tailpipe

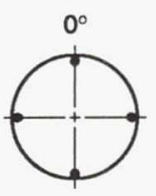

Station 5A1, 5A2 Elbow entrance (without probe)

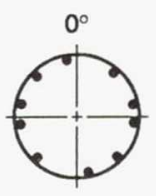

Station 5 A2 Elbow entrance (with probe)

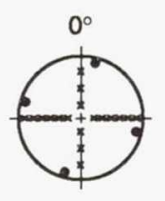

Station 5B1, 5B2 Elbow exit

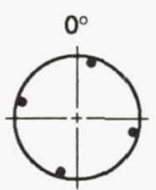

Station 5CS1, $5 \mathrm{CS} 2$ Duct exit

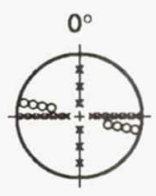

Station $5 \mathrm{C} 1,5 \mathrm{C} 2$ Nozzle inlet

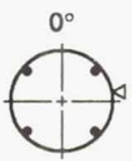

Station N1, N2 Nozzle exit

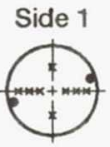

Station V Ventral nozzle inlet

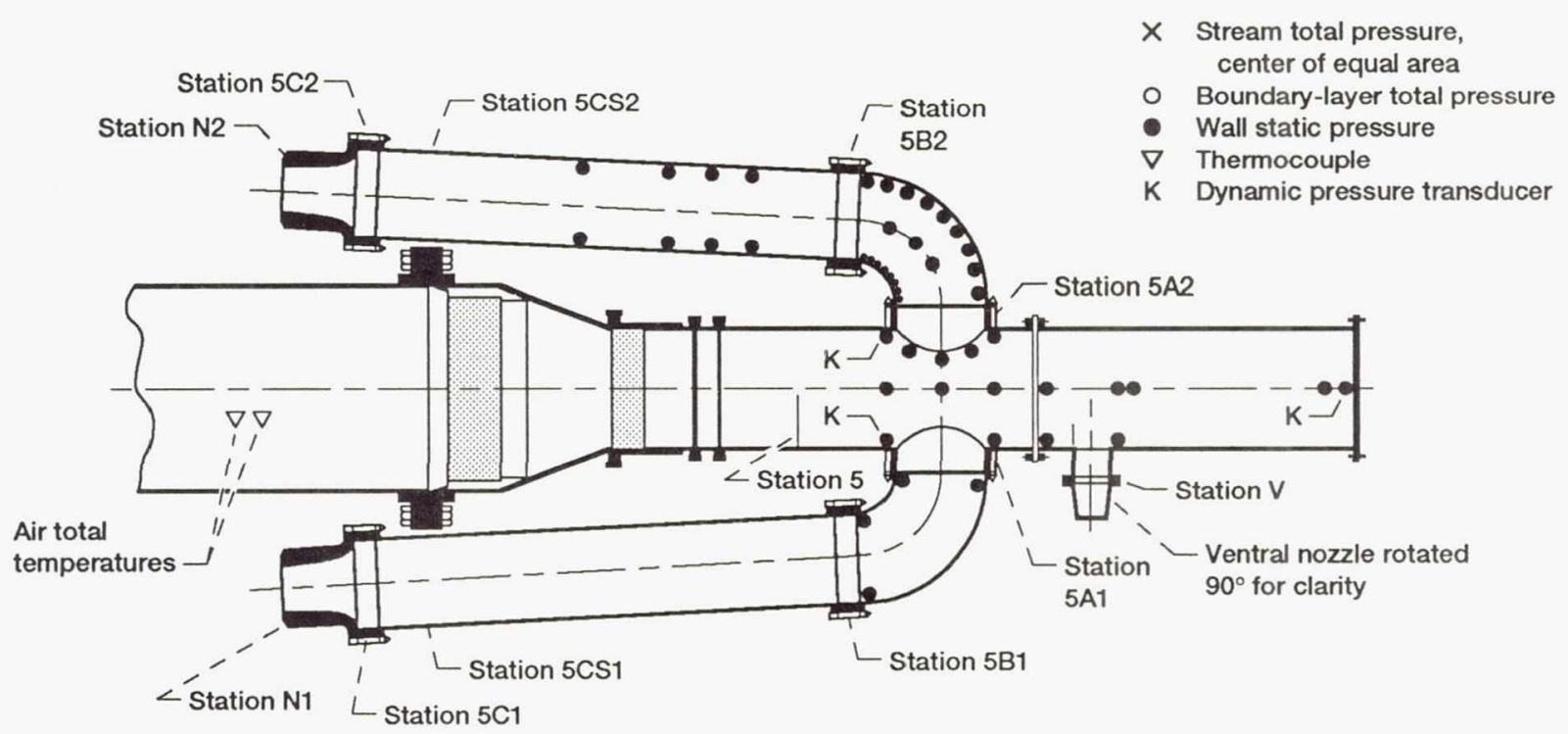

Fig. 4. Station and instrumentation diagrams. Station cross sections drawn looking into flow, with top at $0^{\circ}$.

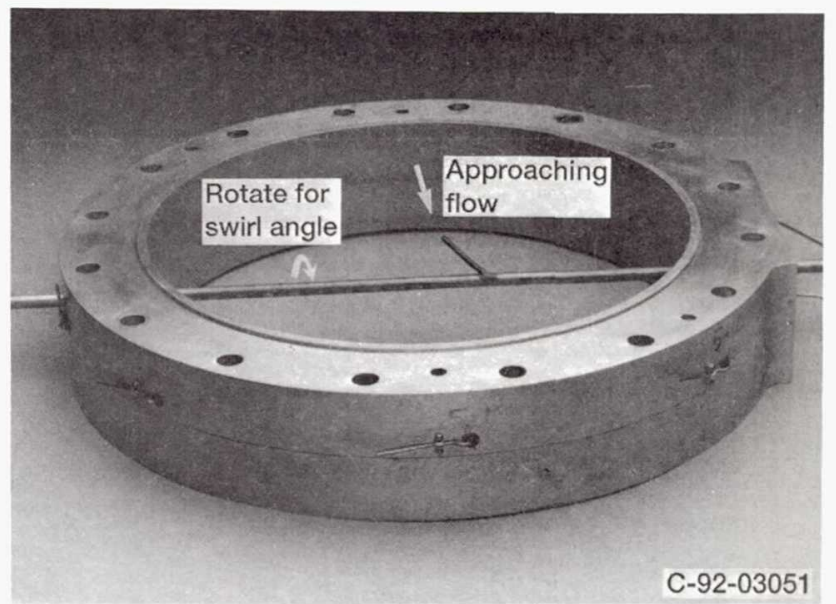

Fig. 5.-Flow angle probe for traverses at Station 5A. Probe shown mounted in instrumentation spoolpiece. 


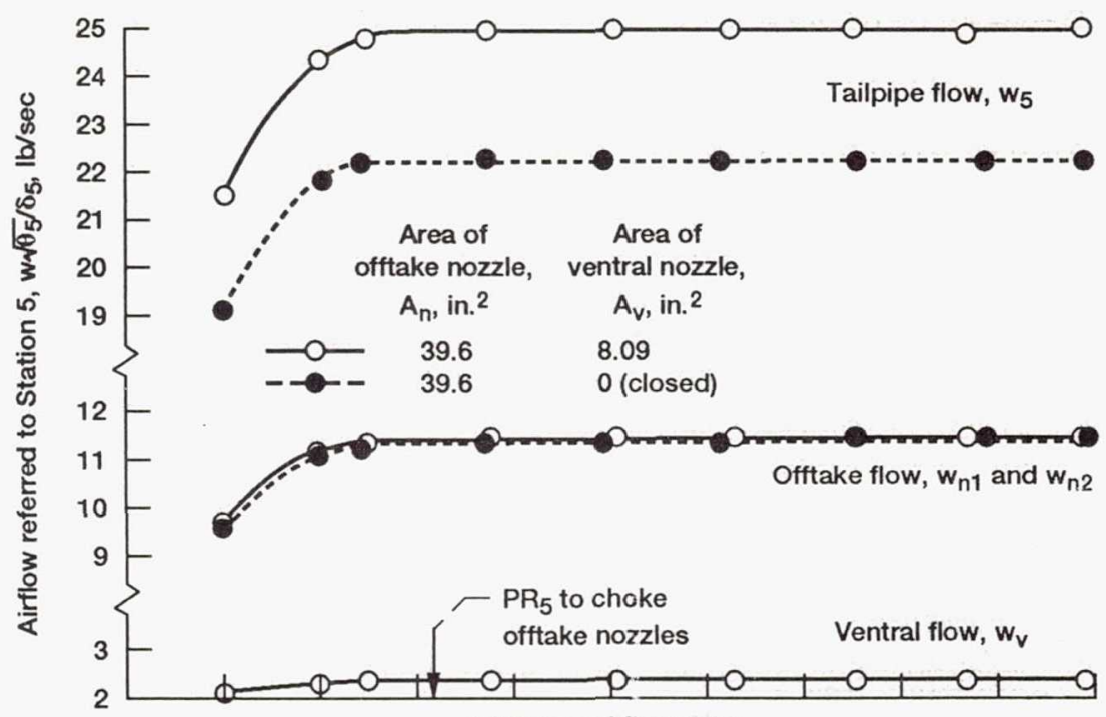

(a) Referred fiow rates.

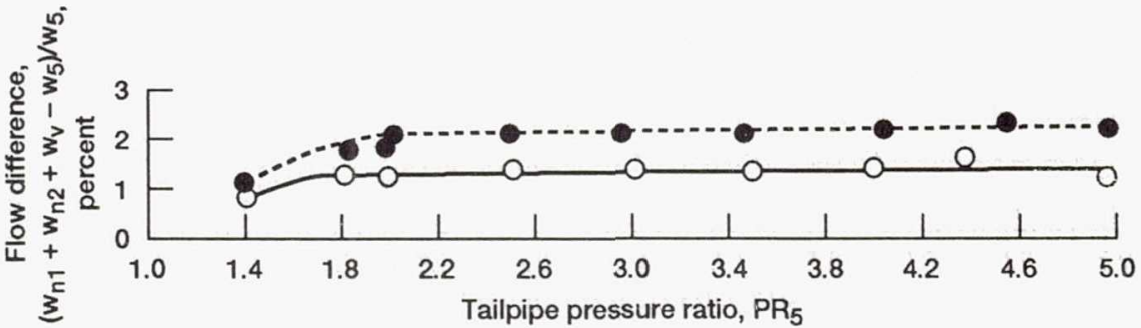

(b) Measured flow difference.

Fig. 6.-Measured airflows with final nozzle sizes. 


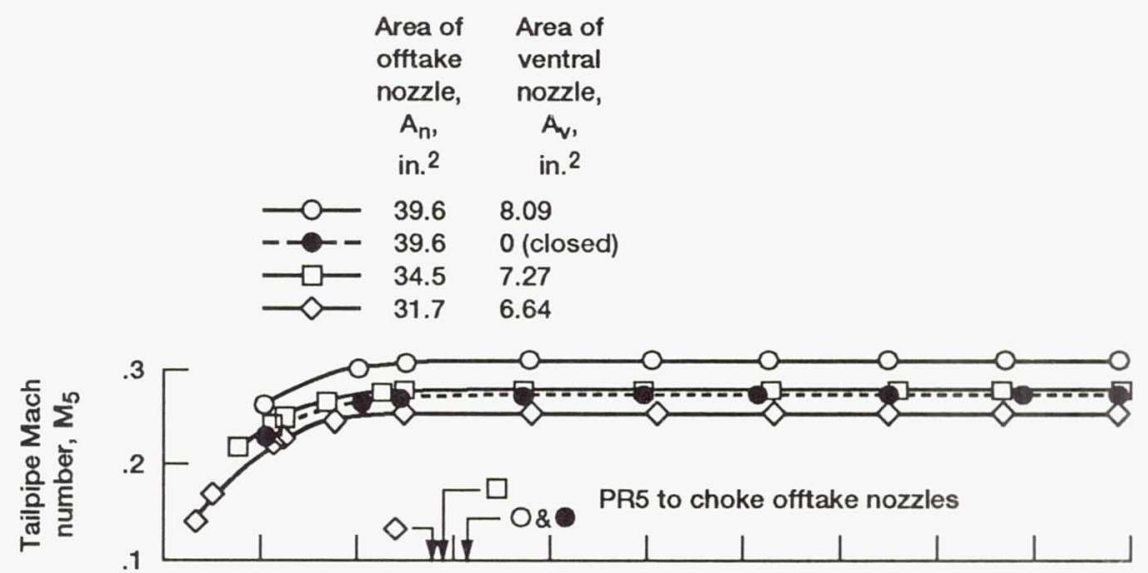

(a) Tailpipe Mach number.

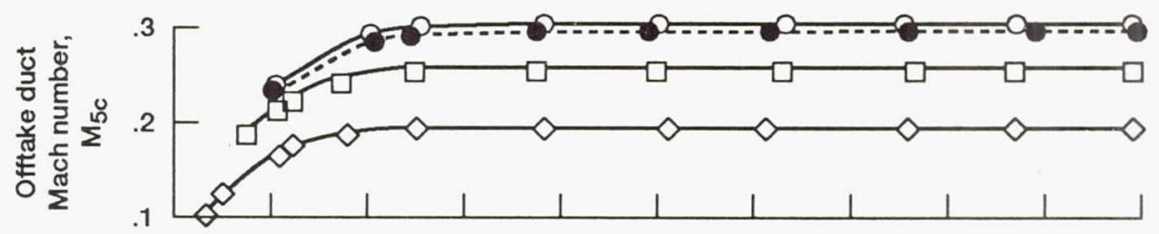

(b) Mach number near end of offtake duct.

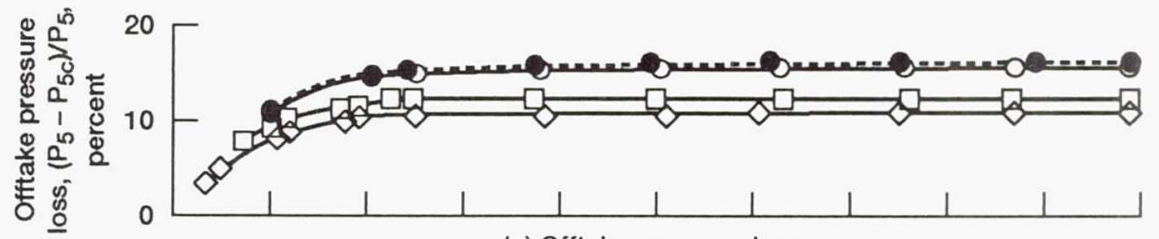

(c) Offtake pressure loss.

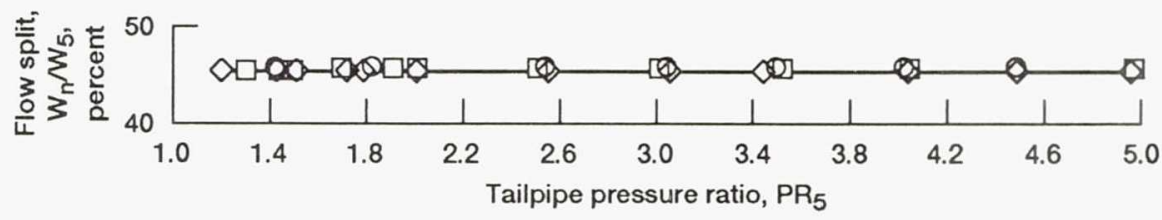

(d) Flow split.

Fig. 7.-Offtake duct performance. 


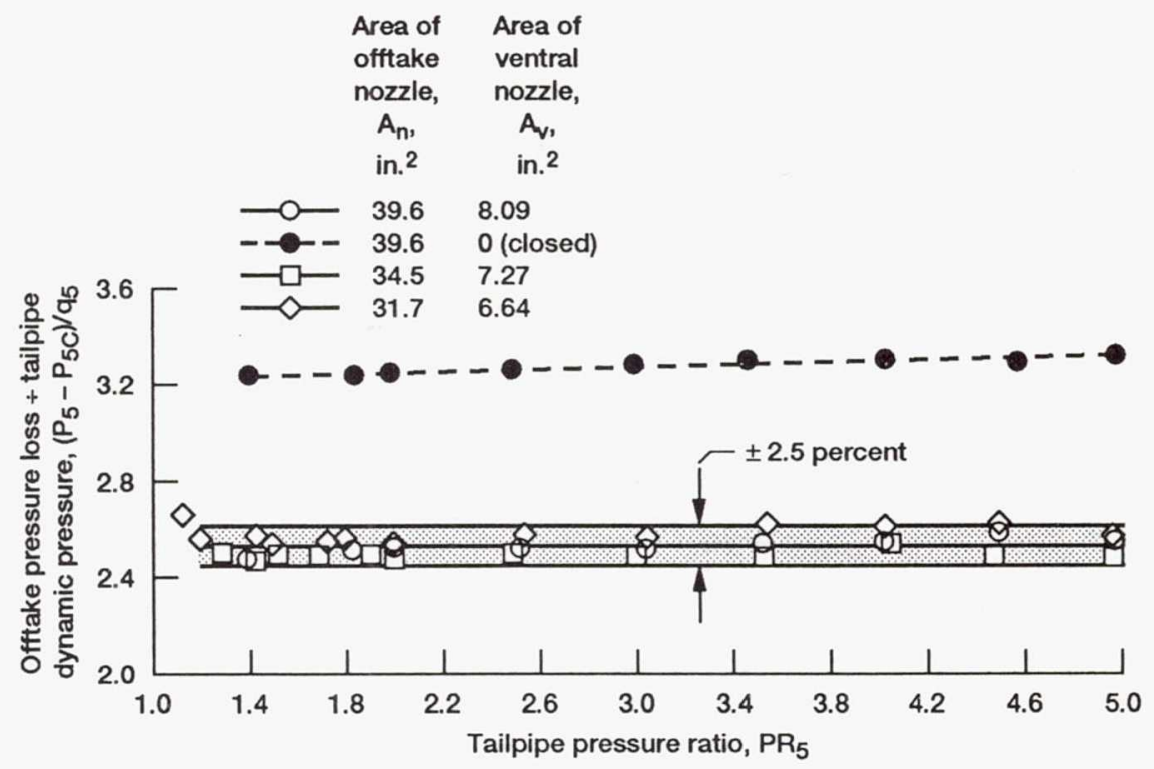

Fig. 8.-Total pressure loss related to tailpipe dynamic pressure. 


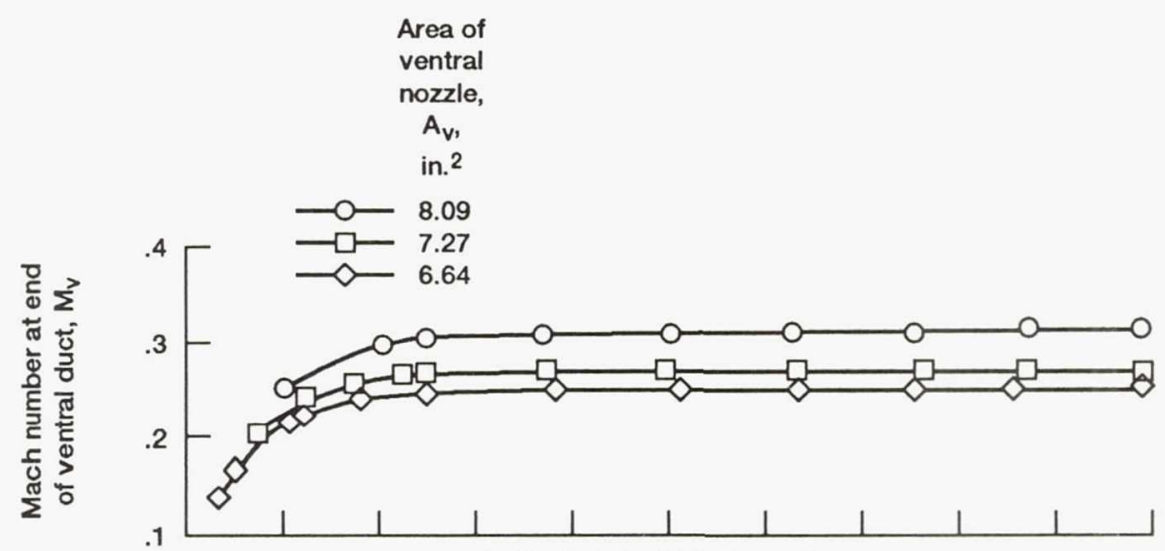

(a) Ventral duct Mach number.

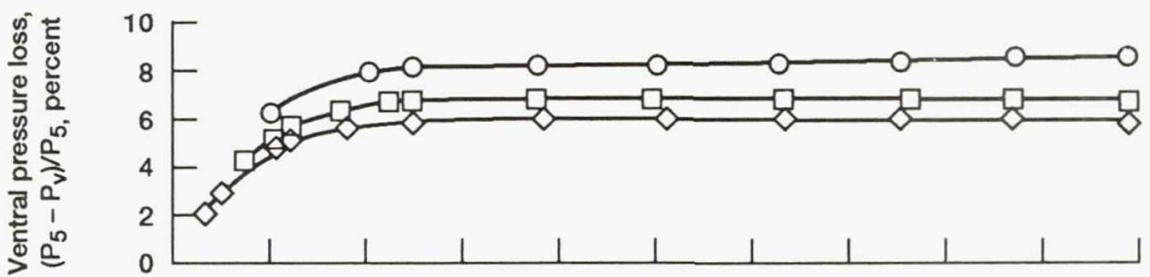

(b) Ventral pressure loss.
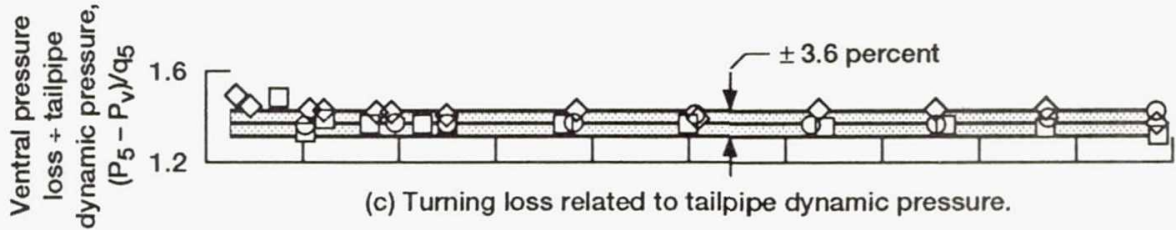

(c) Turning loss related to tailpipe dynamic pressure.

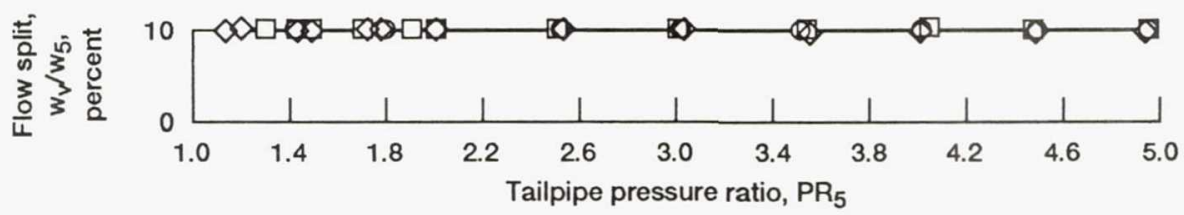

(d) Flow split.

Fig. 9.-Ventral duct performance. 

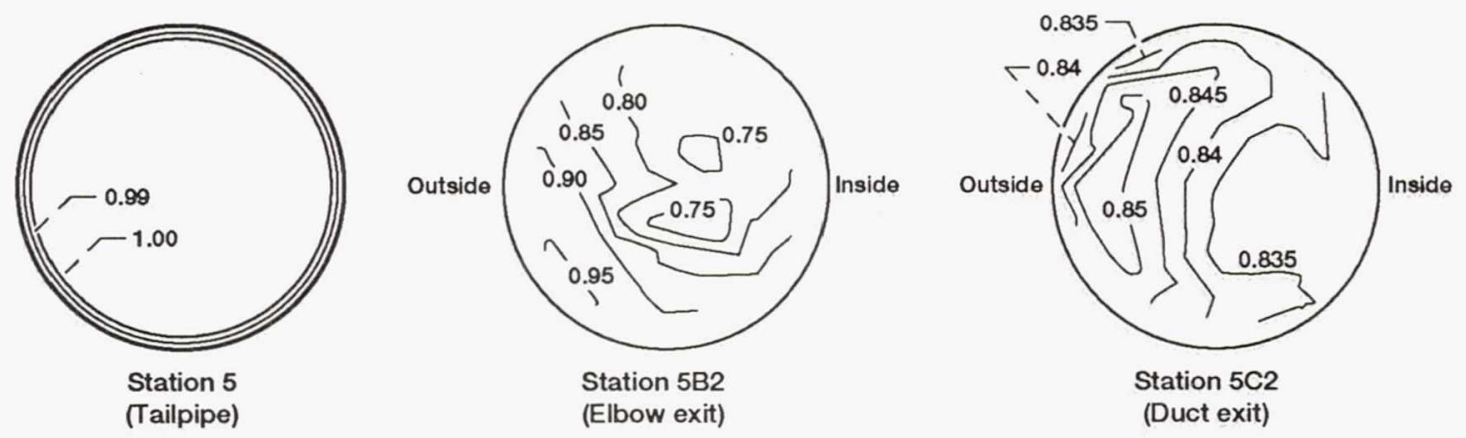

(a) Total-pressure contour plots at $\mathrm{PR}_{5}=4.5$. Numbers show contour level ratioed to $\mathrm{P}_{5}$. Plots shown looking into flow.

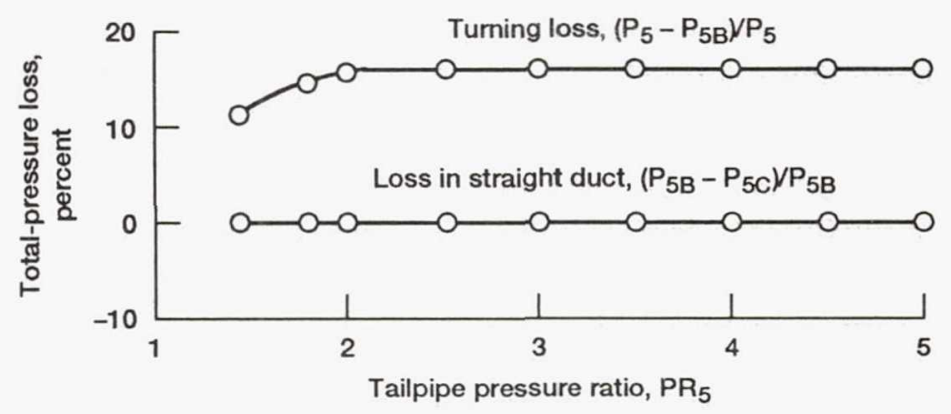

(b) Pressure loss distribution.

Fig. 10. - Offtake total pressure. Final nozzle sizes.

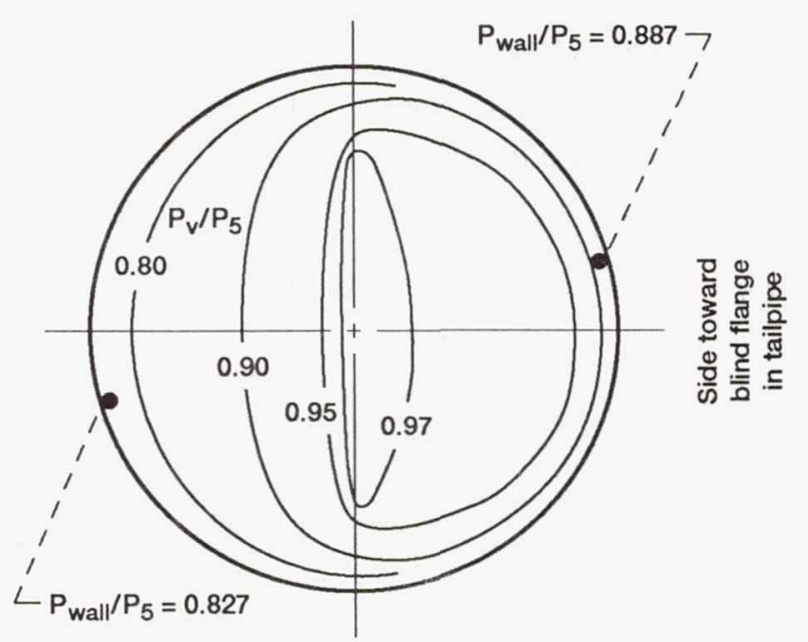

Fig. 11. - Total-pressure contours at Station V (ventral nozzle inlet) estimated from rake data; $\mathrm{PR}_{5}=4.5$. 


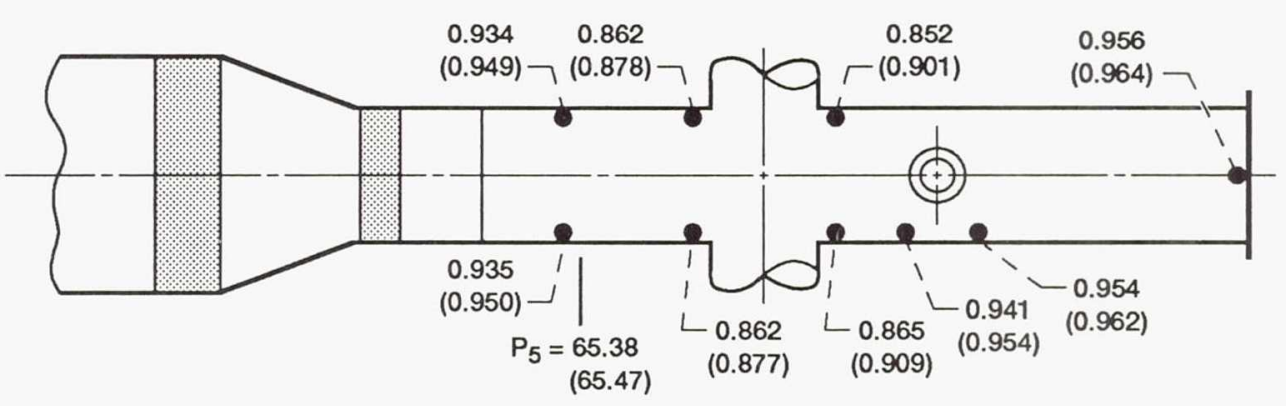

(a) Horizontal section, top view.

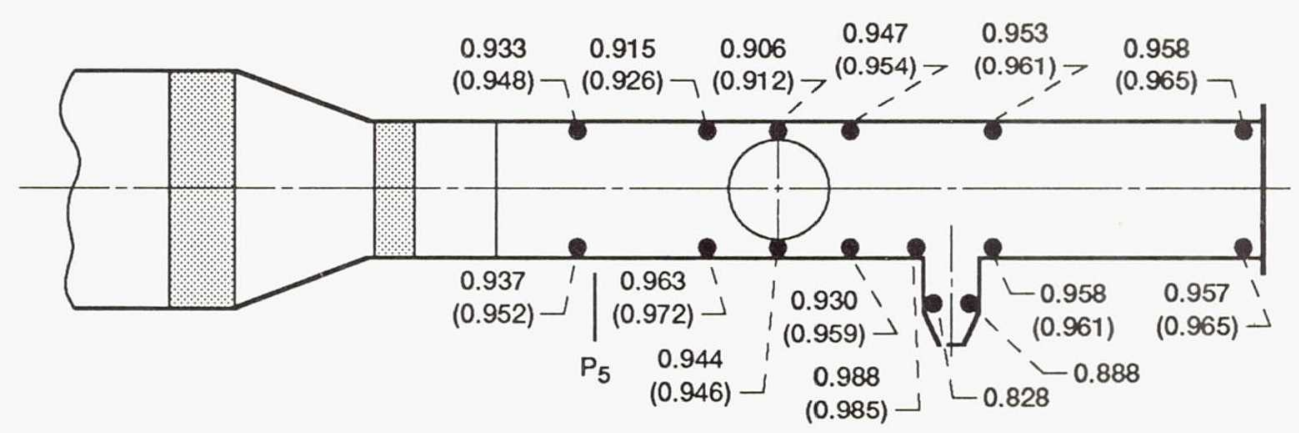

(b) Vertical section, side view.

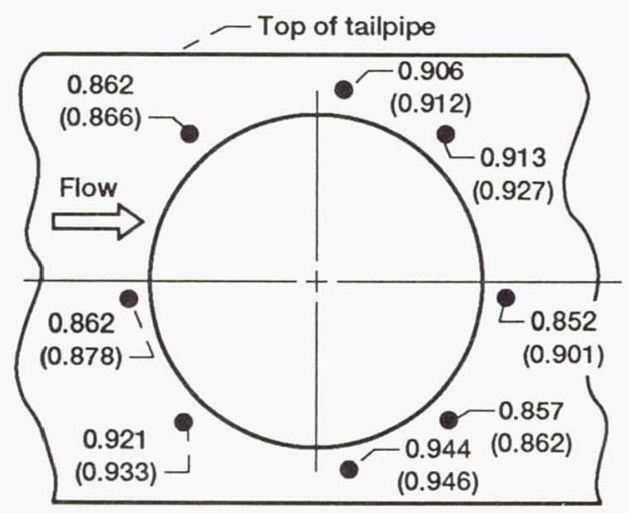

Tailpipe at offtake opening

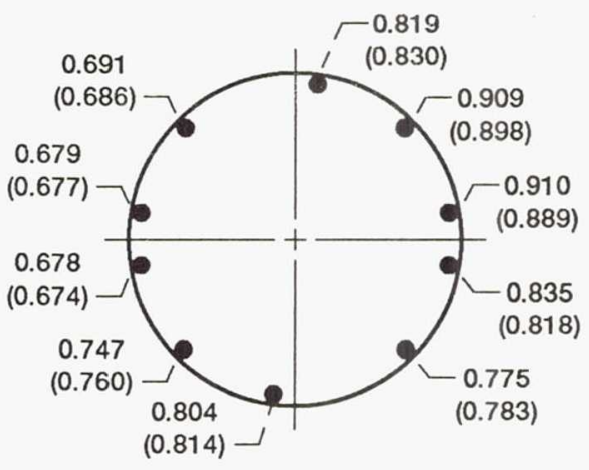

Station $5 \mathrm{~A}$

(c) Offtake opening, looking from tailpipe into opening.

Fig. 12. -Tailpipe wall pressure divided by Station 5 total pressure $\left(P_{w} / P_{5}\right)$ at $P R_{5}=4.5$. Upper numbers are for open ventral nozzle, numbers in parentheses are for closed ventral nozzle. 


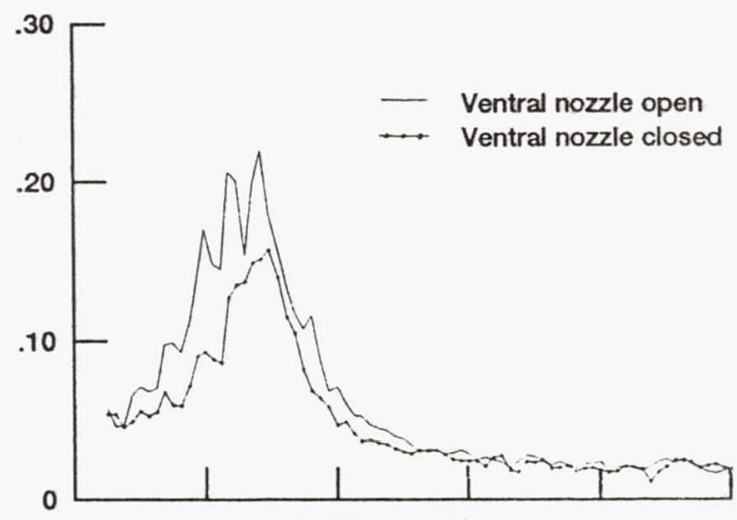

(a) Offtake, side 1 .
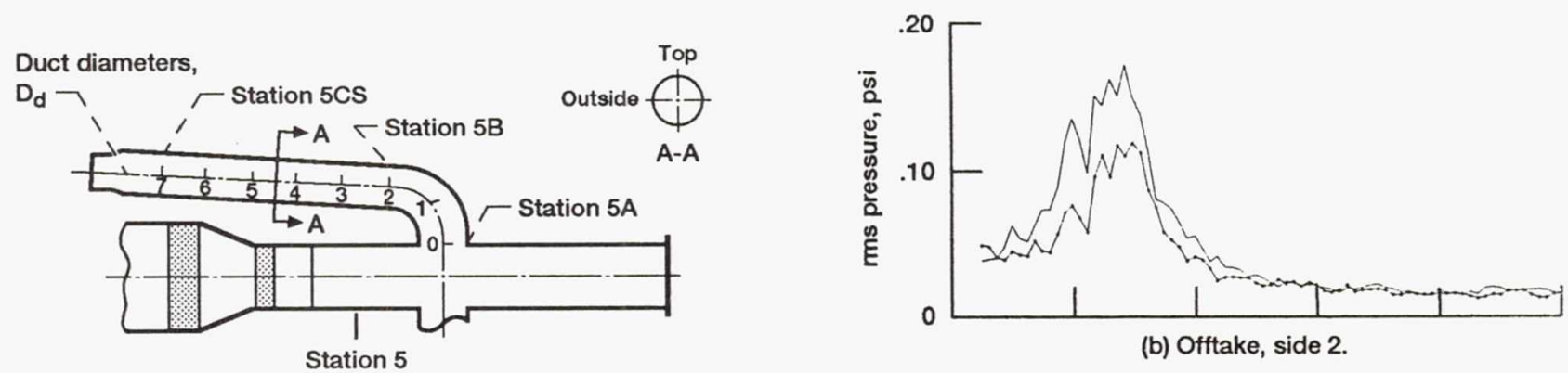

(b) Offtake, side 2 .
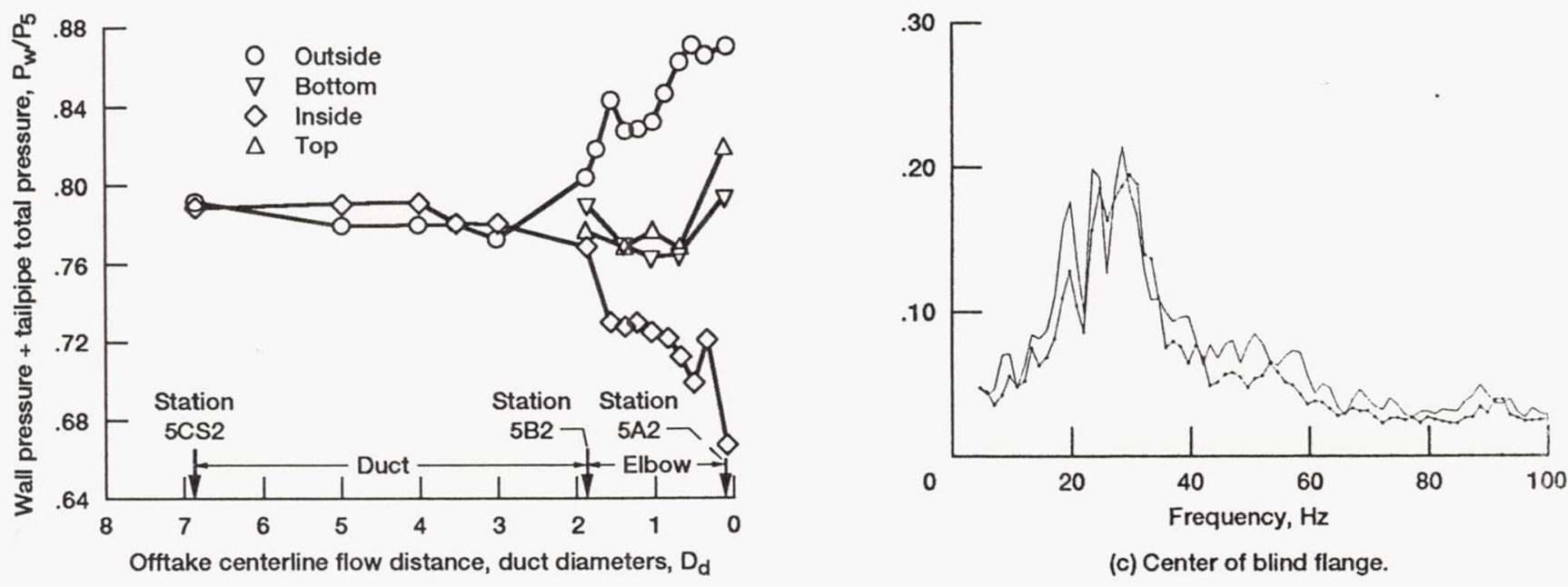

(c) Center of blind flange.

Fig. 13. - Offtake wall pressures for $\mathrm{PR}_{5}=4.5$; ventral open. Results applicable to either offtake side. 

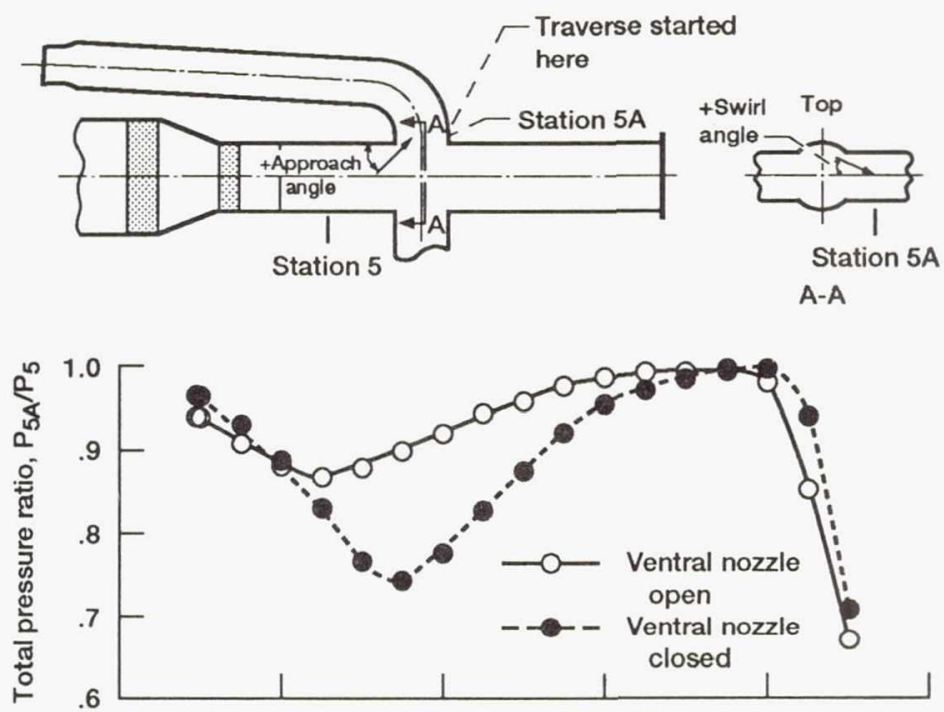

(a) Total pressure ratio.

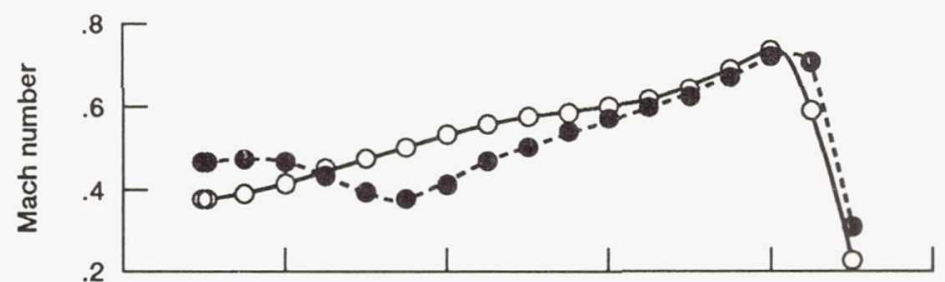

(b) Mach number.

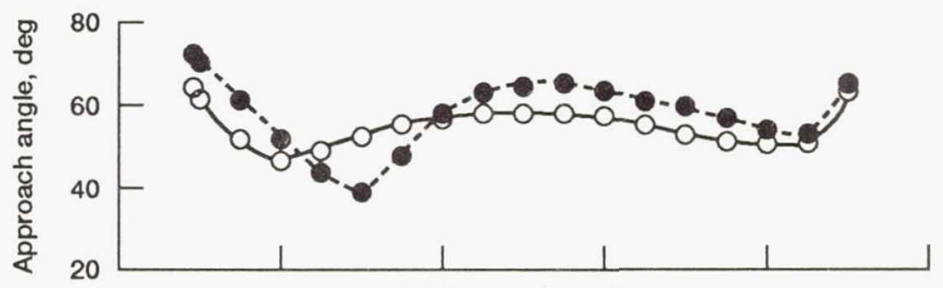

(c) Approach angle.

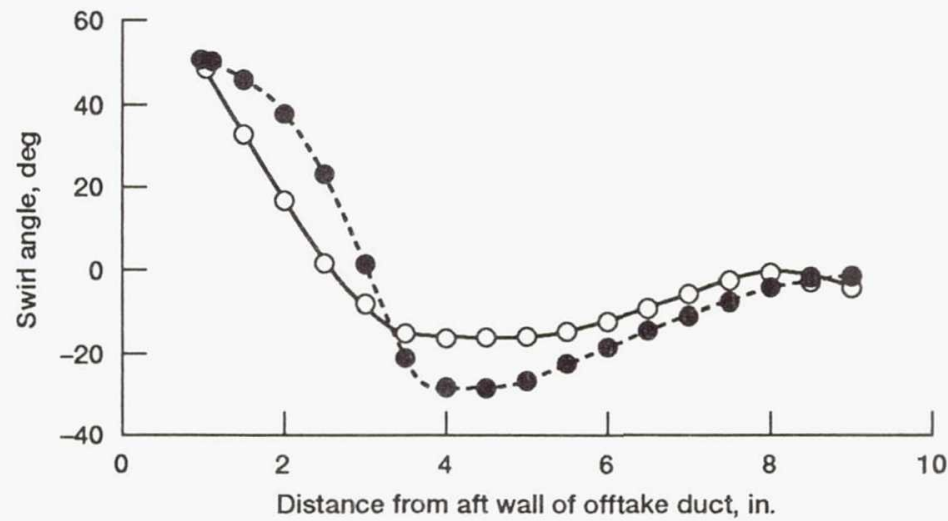

(d) Swirl angle.

Fig. 15.-Flow conditions on offtake horizontal centerline at elbow entrance (Station $5 A$ ) for $\mathrm{PR}_{5}=4.5$. 

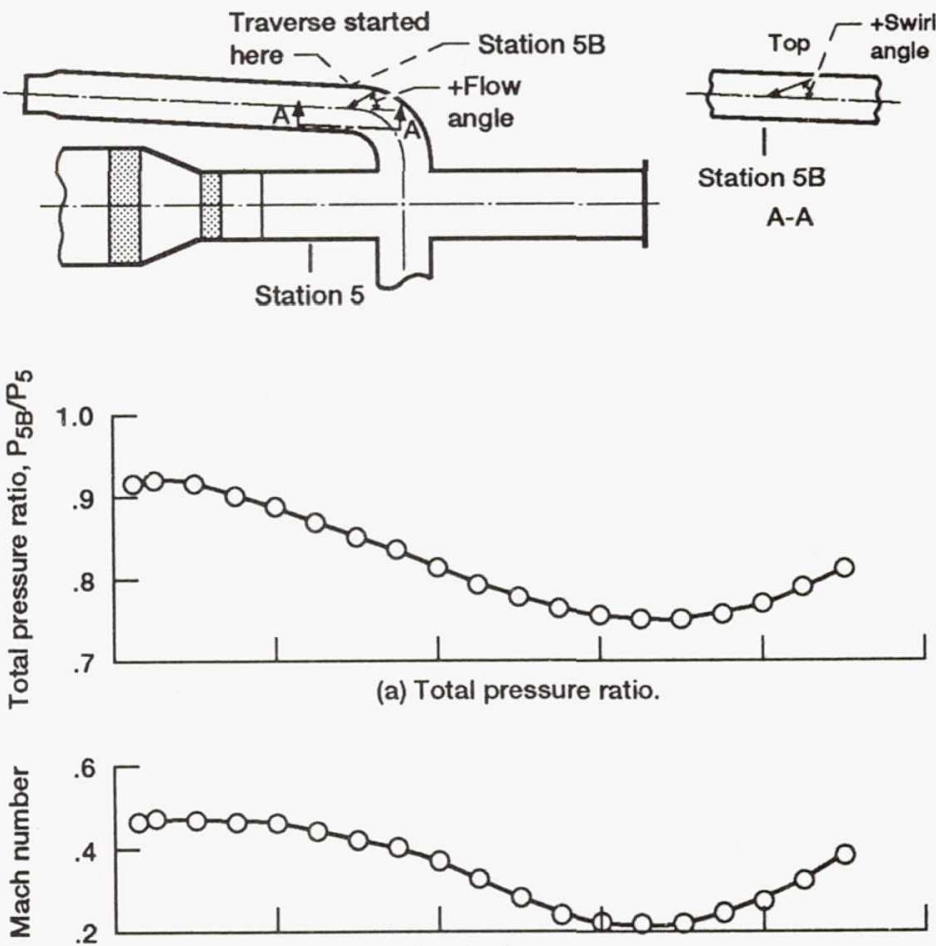

(b) Mach number.

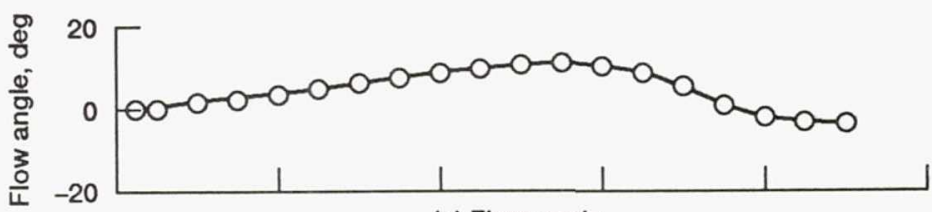

(c) Flow angle.

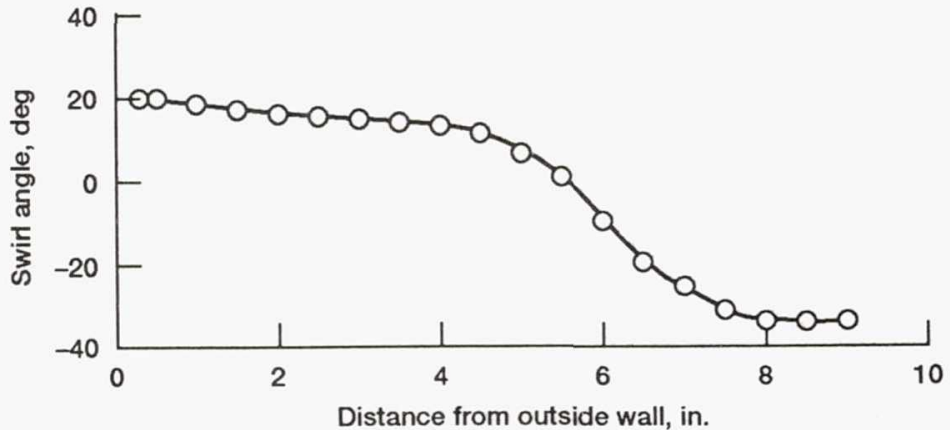

(d) Swirl angle.

Fig. 16.-Flow conditions on offtake horizontal centerline at elbow exit (Station $5 B$ ) for $\mathrm{PR}_{5}=4.5$ with ventral nozzle open. 


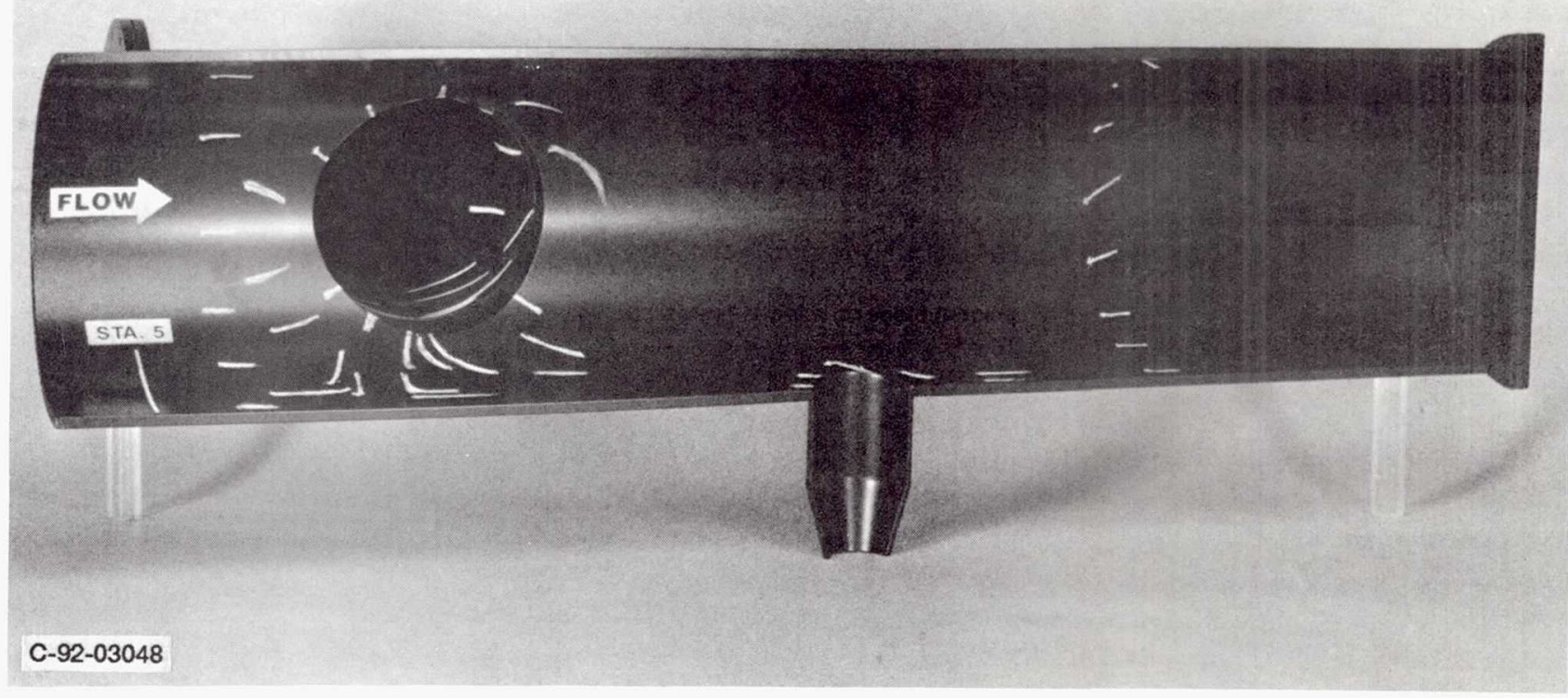

(a) Tailpipe cut at plane of symmetry.

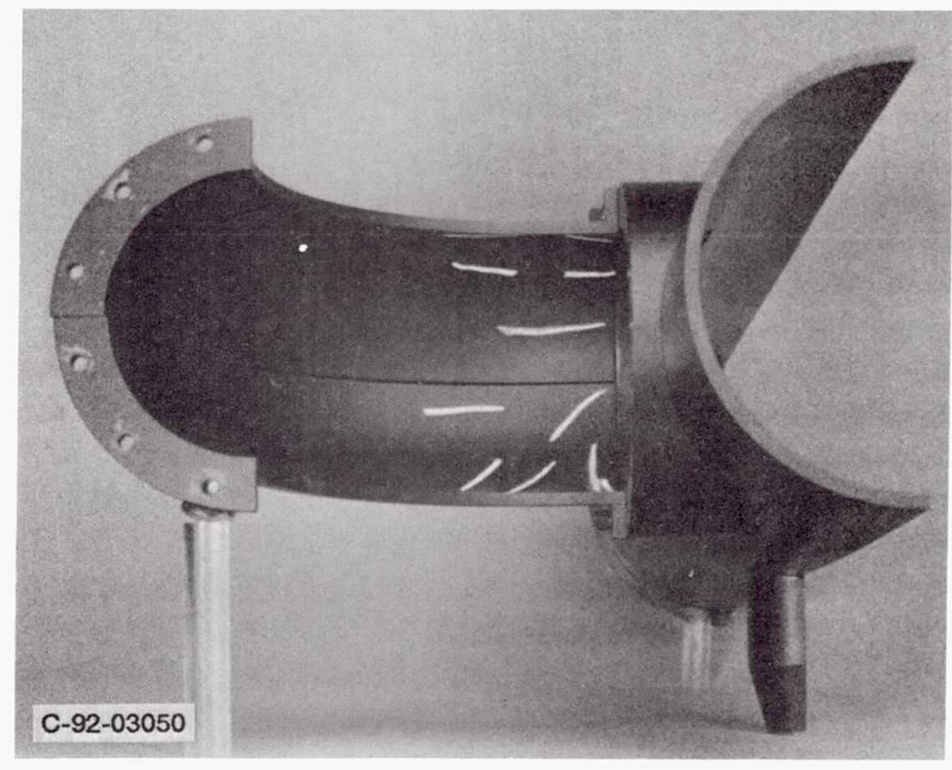

(b) Inside wall of elbow removed.

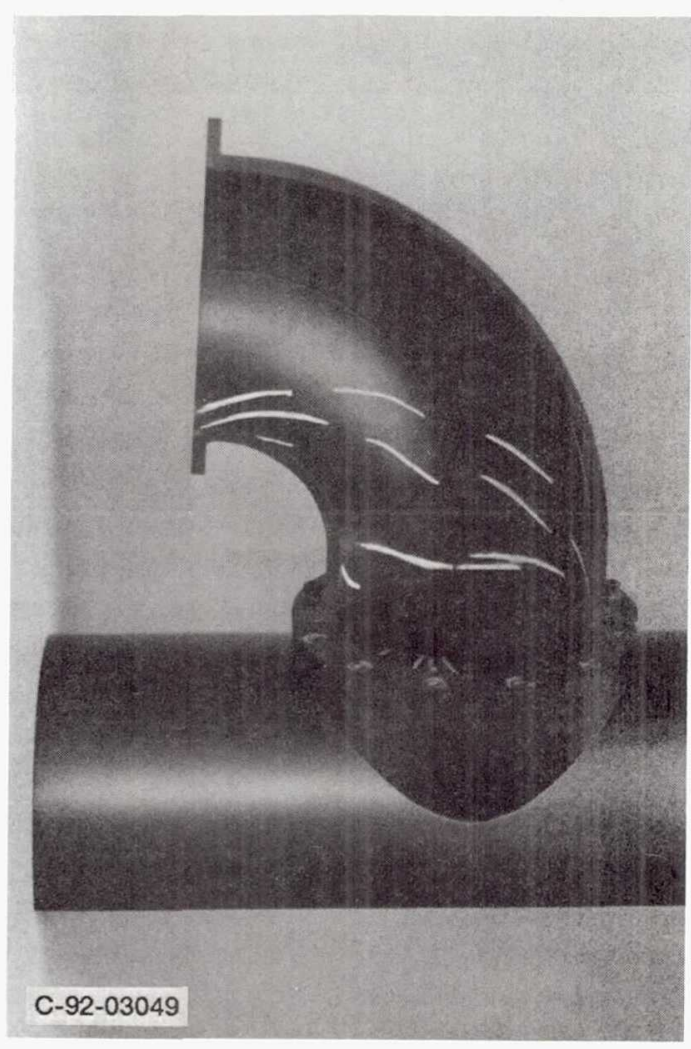

(c) Top wall of elbow removed.

Fig. 17.-Flow visualization streaks on scale mockup of model. 
Public reporting burden for this collection of information is estimated to average 1 hour per response, including the time for reviewing instructions, searching existing data sources, gathering and maintaining the data needed, and completing and reviewing the collection of information. Send comments regarding this burden estimate or any other aspect of this gathering and maintaing in Davis Highway, Suite 1204, Arlington, VA 22202-4302, and to the Office of Management and Budget, Paperwork Reduction Project (0704-0188), Washington, DC 20503.

\begin{tabular}{|l|l|l|}
\hline 1. AGENCY USE ONLY (Leave blank) & $\begin{array}{c}\text { 2. REPORT DATE } \\
\text { July } 1992\end{array}$ & $\begin{array}{r}\text { 3. REPORT TYPE AND DATES COVERED } \\
\text { Technical Memorandum }\end{array}$
\end{tabular}

4. TITLE AND SUBTITLE

Internal Reversing Flow in a Tailpipe Offtake Configuration for

SSTOVL Aircraft

\section{6. $\operatorname{AUTHOR}(\mathrm{S})$}

Jack G. McArdle, Barbara S. Esker, and James A. Rhodes

\section{FUNDING NUMBERS}

WU-505-68-32

\section{PERFORMING ORGANIZATION NAME(S) AND ADDRESS(ES)}

National Aeronautics and Space Administration

Lewis Research Center

Cleveland, Ohio 44135-3191

\section{SPONSORING/MONITORING AGENCY NAMES(S) AND ADDRESS(ES)}

National Aeronautics and Space Administration

Washington, D.C. 20546-0001
8. PERFORMING ORGANIZATION REPORT NUMBER

E-7086

10. SPONSORING/MONITORING AGENCY REPORT NUMBER

NASA TM-105698

AIAA-92-3790

\section{SUPPLEMENTARY NOTES}

Prepared for the 28th Joint Propulsion Conference and Exhibit cosponsored by AIAA, SAE, ASME, and ASEE, Nashville, Tennessee, July 6-8, 1992. Jack G. McArdle and Barbara S. Esker, NASA Lewis Research Center. James A. Rhodes, McDonnell Aircraft Company, St. Louis, Missouri 63166-0516. Responsible person, Jack G. McArdle, (216) 433-3962.

\begin{tabular}{ll|l} 
12a. DISTRIBUTION/AVAILABILITY STATEMENT & 12b. DISTRIBUTION CODE
\end{tabular}

Unclassified - Unlimited

Subject Category 07

13. ABSTRACT (Maximum 200 words)

A generic one-third scale model of a tailpipe offtake system for a supersonic short takeoff vertical landing (SSTOVL) aircraft was tested at the NASA Lewis Research Center Powered Lift Facility. The model consisted of a tailpipe with twin elbows, offtake ducts, and flow control nozzles, plus a small ventral nozzle and a blind flange to simulate a blocked cruise nozzle. The offtake flow turned through a total angle of $177^{\circ}$ relative to the tailpipe inlet axis. The flow split was 45 percent to each offtake and 10 percent to the ventral nozzle. The main test objective was to collect data for comparison to the performance of the same configuration predicted by a computational fluid dynamics (CFD) analysis. This paper gives the experimental results only - the analytical results are published in a separate paper. Performance tests were made with unheated air at tailpipe-to-ambient pressure ratios up to 5 . The total pressure loss through the offtakes was as high as 15.5 percent. All test results are shown as graphs, contour plots, and wall pressure distributions. The complex flow patterns in the tailpipe and elbows at the offtake openings are described with traversing flow angle probe and paint streak flow visualization data.

\begin{tabular}{|c|c|c|}
\hline \multicolumn{3}{|c|}{ 14. SUBJECT TERMS } \\
\hline $\begin{array}{l}\text { 17. SECURITY CLASSIFICATION } \\
\text { OF REPORT }\end{array}$ & $\begin{array}{l}\text { 18. SECURITY CLASSIFICATION } \\
\text { OF THIS PAGE }\end{array}$ & $\begin{array}{l}\text { 19. SECURITY CLASSIFICATION } \\
\text { OF ABSTRACT }\end{array}$ \\
\hline & Unclassınted & Unclassined \\
\hline
\end{tabular}

